The International Journal of

Urologic History $\odot$ www.ijuh.org

\title{
A Tale of Two Journals: An Analysis of History Articles Published from 1973 to 2017
}

\author{
Sutchin R. Patel ${ }^{*}$ \\ From the Department of Urology; University of Wisconsin School of Medicine and Public Health \\ Madison WI \\ *Correspondence: 3 South Greenleaf, Suite J, Gurnee, Illinois; e-mail: sutchin_patel@yahoo.com
}

\begin{abstract}
Introduction: The Journal of Urology (JU) and Urology have different policies regarding the publication of articles devoted to urologic history. JU stopped publishing full length historical articles in 2009. We wished to assess the pattern and frequency of historical article publishing in the two of the largest urologic journals.
\end{abstract}

Methods: We used a PubMed and manually based search of all articles from JU and Urology and categorized each article by subject, especially whether they were wholly and/or subtantially devoted to a historical subject.

Results: From 1973-2000, JU and Urology published 73 and 91 articles on the history of urology respectively. From 19972008, $J U$ experienced an increase in historical articles at a time when the History Forum was begun at the AUA Annual Meeting. Therafter, JU stopped publishing historical articles but Urology has published 35 from 2009-2017 at an average rate of 3.9 articles/year.

Conclusions: The journal Urology, but not $J U$, publishes a history of urology article about every 3 months. The study revealed the need for a journal wholly dedicated to the history of urology.

Key Words: history of urology; journal publications

It was the best of times, it was the worst of times. In 2009, The Journal of Urology made the decision to halt the publication of history articles. Hugh Hampton Young, the journal's founding father, mentioned that historical papers should be published in the journal during his forward in the first issue of The Journal of Urology in 1917. Dr. Young stated "it is therefore evident that some common meeting place is extremely desirable - some medium in which all types of papers upon the field of common interest may appear — archives of Urology - historical, embryological, anatomical, biochemical, pharmacological, pathological, bacteriological, surgical and medical, experimental and clinical."(1) In 1973, Urology was founded. In its first issue, Pablo Morales, its founding editor, wrote that "the success of the journal will depend not only on its appeal to the authors... but also to the audience that reads most of what is published" further stating that "other features will include essays on the history of urology."(2) As two of the most widely read journals of urology, we wished to measure trends in their publication of articles devoted

International Journal of Urology(C) 2021 to the history of urology.

\section{METHODS}

PubMed was used to search for publictions on the history of urology in The Journal of Urology and Urology from 1973-2017. A manual review of the table of contents from both journals of historical articles in the time period (1973-2017) was carried out in order to identify papers missed by search engine capture. Each article was then reviewed to determine its historical subject matter and scope.

\section{RESULTS}

From 1973 to 2017 , a total of 164 articles on the history of urology were published including $73 / 164$ (44.5\%) in The Journal of Urology and 91/164 (55.5\%) in Urology. From 1997 to 2008, The Journal of Urology saw an increased publication of history articles which may have been due to the increased success of the History Exhibit

https://doi.org/10.53101/IJUH71211

Vol. I (i), 3-5, July 2021

Electronically distributed 


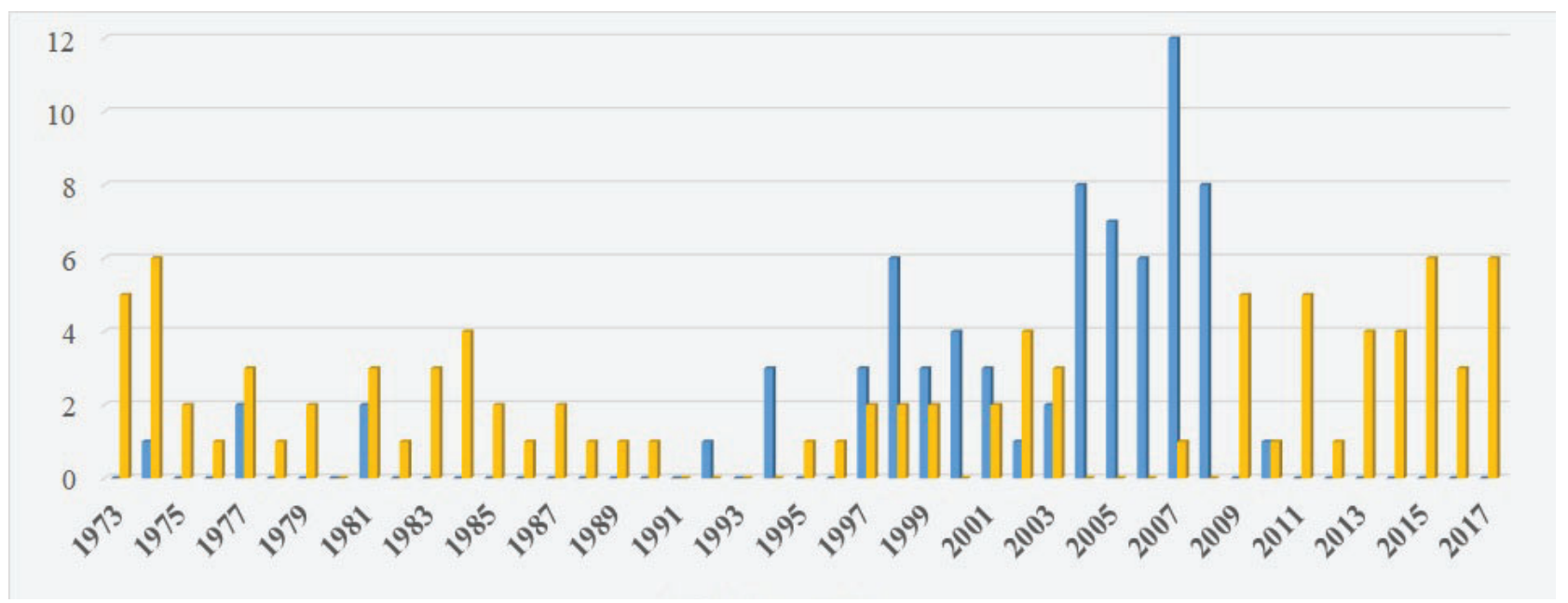

Figure 1. History Articles Published in The Journal of Urology (Blue Bars) and Urology (Gold Bars) from 1973 to 2017

and Forum at the AUA Annual Meeting and the further growth and development of the William P. Didusch Museum in Linthicum, Maryland (www.urologichistory. museum). However, recently both journals have taken a divergent approach to publishing history manuscripts. After The Journal of Urology no longer accepted history articles in 2009, Urology increased the frequency rate of history article publications from 1.3 manuscripts/year (1996-2008) to 3.9 manuscripts/year (2009-2017) when a total of 35 articles were published. (Figure 1)

Querying the topics published in Urology from 2009 to 2017 , historical biography was the most common subject and included 15/35 (42\%) works. Urology in ancient history (9\%), urologic instruments (including the catheter and the cystoscope)(8\%) and the history of urology institutes $\&$ departments (7\%) make up the next most common tier of article topics. When looking at article topics pertaining to a specific urologic organ (generally relating to oncology or surgery involving that organ), the prostate (7\%) and the kidney (5\%) were the most common topics. Female urology, infertility, women urologists and historical topics related to bladder and penis were among the least common topics published (1\% each)(Figure 2 ).

We found that $21 \%$ of the history articles published included either Drs. David A. Bloom or Harry W. Herr as authors, both of whom have been recognized for their contributions with the AUA's William P. Didusch Art and History Award.

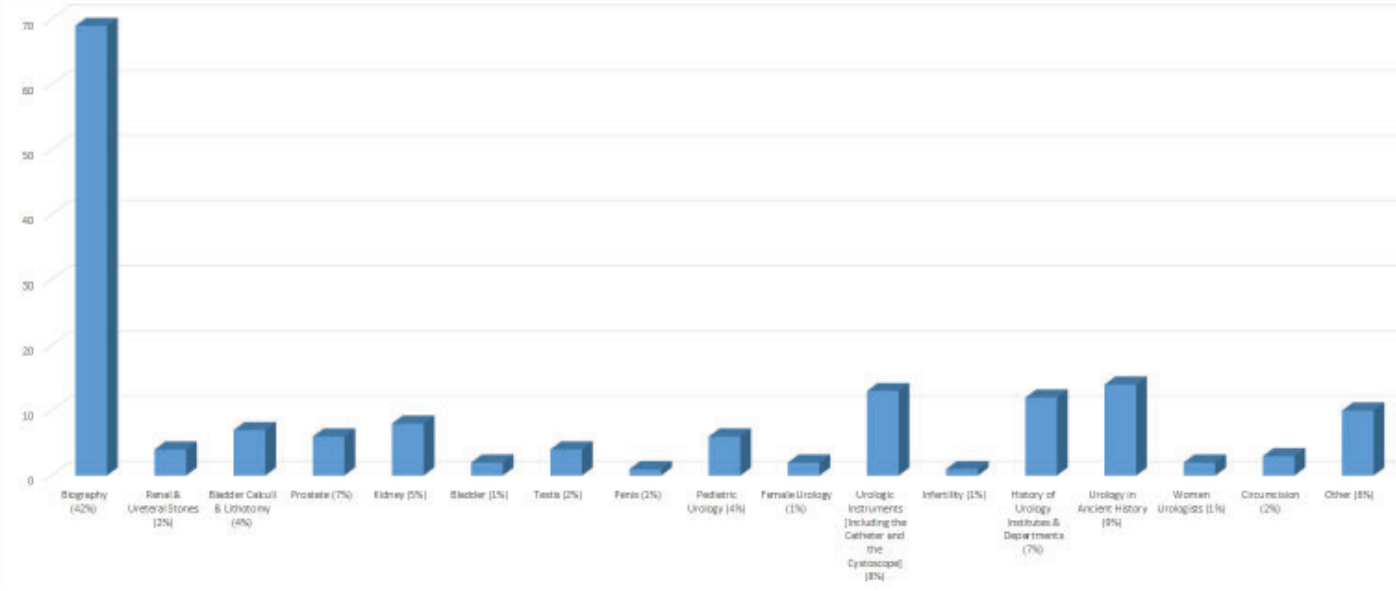

Figure 2. Subjects of historical articles published in the Journal of Urology and Urology, 1973-2017. The largest proportion of manuscripts, about $70 \%$, were "biography" while only $1 \%$ of historical papers were on "female urology", "women in urology", and infertility. 


\section{DISCUSSION}

The field of urology has a rich history which has been preserved at the William P. Didusch Museum and can reach urologists through the medical journals in the field. The journal founders of both The Journal of Urology and Urology discussed the importance of publishing historical articles. However with the halt in historical paper submissions to The Journal of Urology in 2009, we found that Urology has appeared to fill part of the vacuum created to allow for the publication of historical urology papers.

Other urology journals that have published history papers include the Canadian Journal of Urology, Journal of Endourology, BJU International, and The Journal of Pediatric Urology. The Canadian Journal of Urology has uniquely preserved the autobiographical history of giants in our field through its "Legends in Urology" series. In 2008, Gabriel P. Haas, the Editor-in-Chief of the Canadian Journal of Urology announced that a "new section entitled 'Legends in Urology' is introduced with the sole purpose of reviewing major developments in our field and to hear from those responsible for making these advances using their own words to describe their achievements."(3) The journal has produced a "Legend of Urology" article for each issue (6 issues per year) since its inception in 2008. These unique articles have given us a personal view into each of the legend's lives and preserved a first-person account of their career. It should also be noted that the Canadian Journal of Urology has also published papers on the history of urology separate from its Legends in Urology series.

Relatively recently, the Journal of Pediatric Urology in 2019, created a history section for their journal. Dr. Anthony Caldamone, one of the journal's editors, wrote "pediatric urology is a relatively young specialty. However, if you look [at] any abnormality that we currently care for and trace back how we arrived at where we are today, an appreciation of the historic perspective is inevitable... This is the reason why the Editor Board of the Journal of Pediatric Urology has endorsed launching a history section and encourages all of you to take the time to read history and even to document history by contributing articles." (4) Since the creation of its history section, the Journal of Pediatric Urology has published two historical papers, which is already equal to the number of history papers published from its founding in 2005 to 2019.

\section{CONCLUSION}

With the decision to stop accepting historical articles by The Journal of Urology in 2009, Urology has filled the gap and seen a significant rise in the publication of history articles. Though other urological journals have published historical articles, it is clear that there is a need for the formation of a journal dedicated to helping preserve the history of urology. Our review of the articles published illustrates the rise and fall of history publications in The Journal of Urology and the consistent commitment of Urology to history articles. An analysis of the topics covered in these two journals further illuminates what has been written of the past and what still remains to be explored

\section{REFERENCES}

1. Young HH: Forward. J Urol 1917;1:1.

2. Morales PA: Why This Journal? Urology 1973;1:81.

3. Haas GP: Editorial. Can J Urol 2008;15:3950.

4. Koyle MA, Hurwitz RS, Caldamone AA: Editorial. J Pediatr Urol 2019;15:3-4. 